\title{
Degeneration and Regeneration in the Vertebrate Retina
}

\author{
Gabriele Colozza, André Mazabraud and Muriel Perron \\ Laboratory of Neurobiology E Development, UPR CNRS 3294, \\ Université Paris-Sud Orsay, \\ France
}

\section{Introduction}

The human retina is a complex, layered tissue responsible for the perception of the visual stimuli coming from the external environment. Since the visual inputs account for about $30 \%$ of our sensory stimulations, it is not surprising that partial or complete blindness results in a strong decrease of life quality. Several diseases affect the retina, often leading to degeneration of one or several cell types. The damage induced by these diseases is often irreversible, thus leading to a permanent loss of the visual ability.

Over the last decades significant progress has been made to elucidate the molecular basis of retinal degenerative diseases. This knowledge is necessary in order to design valid approaches for the treatment of retinopathies. However, the extreme genetic heterogeneity of these diseases, combined with the complex molecular nature of the underlying degenerative processes, has hampered the design of definitive therapies. Indeed, pharmacological treatments are only partially effective and tend to treat the effect of the disease, not the underlying cause. Furthermore, despite the recent technical advances, drug delivery into the retina may reveal challenging (reviewed in Yasukawa et al., 2011). On the other hand, gene therapy reveals as a promising alternative approach for inherited retinopathies. However, although significant progress has been achieved in treating recessive forms of retinopathies, dominant or multi-factorial forms are more difficult to treat, revealing the current limits of gene-based therapies (Farrar et al., 2010).

Thus, other strategies are needed to treat these diseases. One interesting approach, which will not be covered in this review, is the stem cell-based therapy, where stem cells can be differentiated in vitro and then transplanted to replace dead cells (for a review see Bull and Martin, 2011; Dahlmann-Noor et al., 2010; Locker et al., 2010). Another promising strategy is to promote the regeneration in vivo of the tissues (or organs) affected by the disease. Although the field of regenerative medicine is relatively young, the continuous findings on the mechanisms regulating regeneration in model organisms is improving our knowledge on the regenerative phenomena, and in some cases this information can be used to induce or increase regeneration in particular contexts (reviewed in Stoick-Cooper et al., 2007).

In the first part of this review, we will introduce some of the most common retina degenerative diseases that affect people worldwide, namely retinitis pigmentosa (RP) and age-related macular degeneration (AMD), providing the reader with a general description of these retinopathies. In the second part, we will discuss some of the animal models used 
to mimic particular features of retinal diseases, useful to understand the molecular mechanisms underlying retina degeneration. The information gathered from these models will be instrumental for the design of accurate and effective therapies. In the final part of this chapter we will present animal models, like transgenic frogs or fishes, capable of regenerating their damaged retinas. The use of these models is generating important and promising knowledge on the molecular pathways regulating neural repair, which could one day be used to stimulate retinal regeneration in humans. Thus, we will also review the cellular sources and molecular components playing a fundamental role in in vivo regeneration. Recent studies, aimed at stimulating regeneration processes in vivo by genetic or pharmacological manipulation of signaling pathways, will also be covered in this part.

\section{Retinal diseases}

Retinopathy is a generic term regarding non-inflammatory diseases affecting the retina. The damage usually affects severely the vision ability, especially when the macula (the region of human retina where cone photoreceptors concentrate) or the optic nerve are concerned. Retinopathies can arise as a consequence of other disorders, for example diabetes, or as a consequence of aging. The degeneration process is generally progressive, resulting in severe sight impairment in older patients. Furthermore, although the pathology affects primarily a given cell type, secondary events can arise extending the degeneration to other cell types. In some cases, genetic mutations are the underlying causes of the pathology, which can manifest alone or as a part of a syndromic disease. Due to their prevalence and to the highly debilitating loss of sight they cause, RP and AMD gained much attention in medical and clinical research.

\subsection{Retinitis pigmentosa}

$\mathrm{RP}$ is a group of inherited genetic diseases with a worldwide prevalence of 1 on 4000 individuals in the industrialized world. RP was first described around 1855 by the Dutch ophthalmologist Franciscus C. Donders, while observing pigmented speckles in a patient's degenerating retina. In the most typical form of RP, rod photoreceptors undergo a gradual degeneration, eventually leading to their death which occurs either by apoptotic or nonapoptotic mechanisms (reviewed in Berson, 1993; Chang et al., 1993; Hartong et al., 2006; Sancho-Pelluz et al., 2008). As a result, the loss of rods compromises the peripheral and night vision, as evidenced by the restriction of visual field (tunnel vision) and night blindness in RP patients.

As the disease progresses, the cones residing in the macula are also affected, degenerating after the rod photoreceptor death. As a consequence, other symptoms are manifested like color-blindness and loss of the central vision, resulting in total visual impairment (Berson, 1993; Hartong et al., 2006). The onset of RP symptoms is variable: some patients develop visual impairments during childhood, while others remain asymptomatic until midadulthood. There is no treatment to cure patients with RP, who usually become legally blind by the $40^{\text {th }}$ year of age, because of a severe constriction of the visual field. Retinas of patients affected by RP undergo dramatic changes, as can be observed by fundus examination. Besides accumulation of pigmented deposits, retina atrophy, attenuation of retinal vessels and reactive gliosis are also associated with RP (reviewed in Hamel, 2006). 
The pattern of inheritance of RP is complex and depends on the gene being affected. Generally, RP presents as a monogenic disease that can be inherited as autosomal dominant ( $24 \%$ of the cases), recessive $(41 \%)$, or X-linked $(22 \%)$. However, the remaining of the cases are considered to result from non-Mendelian inheritance or environmental factors (reviewed in Wright et al., 2010). So far, more than 45 genes have been shown to be involved in RP (http://www.sph.uth.tmc.edu/retnet/), which highlights the high genetic heterogeneity of the disease. Nonetheless, the significance of gene mutations in RP, as well as the molecular mechanisms leading to photoreceptors degeneration, is still poorly understood.

\subsection{Age-related macular degeneration}

AMD is a group of conditions that affect the central retina, particularly the macula. AMD represents the leading cause of vision loss in individuals above the $60^{\text {th }}$ year of age, with a prevalence of $30 \%$ among people older than 75 . Among these patients, about $10 \%$ show signs of advanced AMD, which is characterized by an extensive deterioration of central vision, with a tremendous impact on normal daily activities such as reading or deambulating (reviewed in Prasad et al., 2010). Age is one of the risk factors for this disease. It is estimated that, since the life expectancy is increasing, with an escalation of people reaching the age of 70 or greater, the prevalence of AMD in 2020 will double (for reviews, see Liutkeviciene et al., 2010; Prasad et al., 2010). Besides age, other factors such as oxidative stress and genetics are known to play a major role in the onset of the disease. However, it is important to note that the precise causes of AMD remain still unclear. Although AMD affects mainly elderly people, young may also be affected in the context of genetic (monogenic) disorders characterized by early onset, affecting people younger than 40 (reviewed in Rattner and Nathans, 2006).

Initially, AMD is characterized by the presence of large and poorly demarcated "drusen", aggregates of lipids and proteins which accumulate between the retinal pigmented epithelium (RPE) and the Bruch's membrane. RPE underlying these drusen displays some abnormalities such as hypo-pigmentation. Although at this stage there is no significant impairment on visual acuity, there is a high risk of progression to more severe forms of AMD, or late AMD. Late AMD is characterized by localized degeneration of RPE (geographic atrophy or dry - non exudative - AMD). Eventually, new blood vessels from the choroid above the RPE can grow into the macula, leading to the so-called exudative (or wet) AMD. These blood vessels are very fragile and may result in local bleeding, leading to blurry vision and visual distortion. Ultimately, these lesions can form a fibrous scar, which typically result in irreversible loss of central vision (Prasad et al., 2010; Rattner and Nathans, 2006). It is important to note that, although RPE cells are primarily affected by AMD, it is the subsequent loss of photoreceptors that accounts for vision loss.

As stated above, genetics play also a role in macular degeneration. In particular, some inherited forms are known, characterized by early (or juvenile) onset. For example, Best Vitelliform Macular Degeneration (BVMD) and Stargardt-like disease are both dominant inherited juvenile forms of macular degeneration (reviewed in Vasireddy et al., 2010; Xiao et al., 2010). These diseases are characterized by extensive accumulation of lipofuscin, yellow granules containing lipids, atrophy of the RPE and loss of the central vision, all clinical features shared by several forms of age-related macular degeneration. However, clinical profiles of inherited macular degeneration may vary among patients, indicating the intervention of other factors in modelling the disease. One of such factors could be oxidative 
stress. Interestingly, susceptibility to the onset of macular degeneration is increased by oxidative damage that leads to cumulative mutations in mitochondrial DNA of retina cells (reviewed in Jarrett et al., 2010).

\section{Animal models for retinopathies}

Because animals develop retinal diseases with similar traits as in humans, they are commonly used to improve our understanding of the molecular pathogenesis of hereditary retinal degeneration. Animal models can also serve to screen compounds for therapeutic use. Different species such as mice, rats, dogs, cats and even pigs have contributed to the study of retinal degeneration (reviewed in Fletcher et al., 2011; Rivas and Vecino, 2009). Describing all these different models is beyond the aims of this review. Thus, in this section we will focus on some models mimicking retina degeneration, which greatly contributed to the elucidation of molecular pathways underlying the different retinopathies.

\subsection{Mouse models for retina degeneration}

Natural mutant mice or knock-out animals allowed to identify several important genetic factors involved in retina degeneration. Importantly, these genes share analogous mutations in human. In addition, the effects on retinal structure and function of gene mutations associated with retinal diseases can also be tested by means of transgenesis. In many cases the proteins encoded by these genetic factors were shown to be sensible targets for pharmacological treatments or gene therapy, giving important results in terms of clinical and medical investigation. Below, we will give a brief overview of the different mouse models used to mimic RP or AMD, describing the degenerative mechanisms they contributed to elucidate (see also Table 1).

\subsubsection{Mouse models for RP: Mutations in rhodopsin}

The rod visual pigment rhodopsin, a G-protein coupled receptor that initiates the visual transduction cascade, was the first protein found to be mutated in RP. Rhodopsin mutations are responsible for $30-40 \%$ of autosomal dominant forms of RP (reviewed in Fletcher et al., 2011; Wang et al., 2005). One of the most common mutation in human rhodopsin is the substitution of proline for histidine in position $23(\mathrm{P} 23 \mathrm{H})$ (Dryja et al., 1990). Mice expressing such mutated rhodopsin develop significant photoreceptor degeneration, with a consequent decrease in visual function (Olsson et al., 1992). Importantly, photoreceptor degeneration was also observed in control transgenic mice overexpressing wild type rhodopsin. Together, these data suggested that the expression levels of either normal or aberrant rhodopsin may play a role in triggering cell death (Olsson et al., 1992). Based on cell culture and transgenic mice, it was shown that most rhodopsin mutants interfere with the folding, the stability and/or the transport to the membrane of rhodopsin protein (Kaushal et al., 1994; Roof et al., 1994; Wang et al., 2005). However, since different results are obtained in various animal models, the exact mechanisms underlying rhodopsin-dependant photoreceptor cell degeneration is still not well understood and remains controversial. Therefore, generating additional, more appropriate, animal models is still an issue. Along this line, a knock-in mice model expressing $\mathrm{P} 23 \mathrm{H}$ rhodopsin was recently reported and highlighted defective glycosilation and rapid degradation of the mutant protein, in addition to disorganization of the rod outer segments, which may account for photoreceptor degeneration (Sakami et al., 2011). 


\subsubsection{Mouse models for RP: Mutations affecting phototransduction pathway}

Among the genes involved in phototransduction cascade, phosphodiesterase 6 (PDE6) genes are the most studied. Phosphodiesterase 6 is a hetero-tetrameric enzyme consisting of one $a$, one $B$ and two $\gamma$ subunits, involved in cGMP (cyclic guanosine monophosphate) breakdown. Mutations in any of the three subunits give rise to recessive forms of RP. Most of the knowledge on the molecular mechanisms concerning this specific form of RP comes from studies on one mouse strain, known as Retinal degeneration 1 ( $r d 1)$, where the PDE6B gene, encoding the $\mathbb{B}$ subunit, is mutated. The corresponding mutation in humans accounts for about $5 \%$ of the recessive forms of RP (http://www.sph.uth.tmc.edu/retnet/). These animals are natural loss of function mutants closely mimicking the human disorder. In these mice, non-functional PDE6B protein leads to accumulation of high levels of cGMP in the rods (Paquet-Durand et al., 2009). Thus, the sustained levels of cations contribute to constantly depolarize rod photoreceptors, eventually causing these cells to die. More recently, it has been shown that cyclic nucleotide-gated ion channels (CNGs) play a pivotal role in the PDE6B-dependent cell death mechanism (Paquet-Durand et al., 2011). These channels allow the influx of $\mathrm{Na}^{+}$and $\mathrm{Ca}^{2+}$ inside the cells in a cGMP-dependent manner, and increased levels of cGMP are correlated with excessive intracellular concentration of $\mathrm{Ca}^{2+}$ ions. Indeed, as a confirmation of these results, knock-out mice for Cngb1 gene (lacking rod CNGs) in a $r d 1$ mutant background, show a substantial rescue of rod and cone cellmorphology and function, compared to single $r d 1$ mutants. These double mutant mice show also an increased rate of photoreceptor survival compared to the single mutant $r d 1$ (PaquetDurand et al., 2011). Thus, the results reported here argue for a major role of CNGs and calcium in triggering rod degeneration.

\subsubsection{Mouse models for RP: Mutations affecting photoreceptor structural proteins}

Photoreceptor outer segments are continuously renewed to replace proteins and lipids that are damaged by light and highly oxidative environment. Maintenance of the integrity and renewal of the outer segment disk membranes is thus critical for correct photoreceptor function. Peripherin is an integral membrane protein that localizes to the rim of photoreceptor outer segments and was proposed to act as a structural element for the outer segment membranes (Connell and Molday, 1990; Molday et al., 1987). Mutations in Peripherin (PRPH) are a common cause for autosomal dominant RP, accounting for about $5 \%$ of the cases (reviewed in Boon et al., 2008). Retina degeneration slow (rds) mice are naturally occurring homozygous mutants, carrying a mutation in the Peripherin gene (Connell et al., 1991; Travis et al., 1989). These mice are characterized by photoreceptor degeneration and abnormal morphological features in the outer segment discs. Transgenic mice, carrying an aminoacid substitution (P216L) in the Peripherin protein were generated (Kedzierski et al., 1997). These mice exhibited photoreceptor loss proportional to the level of transgene expression. Importantly, photoreceptor outer segments displayed abnormal shortening and central lacunae, confirming the hypothesized role for Peripherin in the stabilization of outer segment architecture and thereby in the viability of photoreceptors. The underlying mechanisms remain however to be further explored for the future development of therapeutic strategies.

\subsubsection{Mouse models for RP: Mutations affecting ciliary proteins}

The photoreceptor connecting cilium, a structure that connects the inner (having the metabolic machinery) with the outer segment (containing phototransduction proteins), 
mediates trafficking of factors involved in phototransduction. It is therefore not surprising that mutations in photoreceptor cilium proteins have been reported to cause RP, and in particular X-linked RP, which is the most severe form in terms of age onset and progression (reviewed in Hosch et al., 2011; Murga-Zamalloa et al., 2009). Mutations in retinitis pigmentosa GTPase regulator (RPGR) and retinitis pigmentosa GTPase regulator interacting protein (RPGRIP) genes account for about $70 \%$ of $X$-linked RP (Vervoort et al., 2000). RPGR protein localizes to the connecting cilium, and mice knock-out for this protein exhibit progressive photoreceptor degeneration. Notably, basal disc membranes were strongly disorganized in these mice, and opsin mislocalization or reduction was observed (Hong et al., 2000). Even though RPGR is a ciliary protein, the cilium structure seems to be well preserved in knock-out mice. This may indicate that RPGR regulates activities like protein transport along the cilium, more than its biogenesis/maintenance. Consistent with this, it was recently reported that RPGR interacts with RAB8A, which is a critical GTPase involved in photoreceptor protein trafficking, and that this interaction may account for photoreceptor degeneration in patients with RPGR mutations (Murga-Zamalloa et al., 2010). RPGRIP knock-out mice also show photoreceptor degeneration and outer segment discs appear oversized and disorganized (Zhao et al., 2003). Importantly, in these mice RPGR protein appears mislocalized, indicating that RPGRIP is involved in tethering RPGR to the connecting cilium. RP1 is another ciliary factor, a photoreceptor-specific microtubuleassociated protein, whose mutation gives rise to common forms of autosomal dominant RP (5-10\% of the cases). Mice expressing C-terminal truncation of this protein (resembling human disease-associated mutations) were created (Liu et al., 2003). These mice developed significant photoreceptor degeneration. Analysis of the phenotype indicated that RP1 could play a fundamental role in the organization of the outer segment discs. Given the important phenotype heterogeneity observed in patients with cilium associated RP, it is critical to further characterize animal models carrying mutations in cilium proteins to better understand the pathogenesis of these RP diseases.

\subsubsection{Mouse models for age-related macular degeneration}

Due to its complex genetic components and to the role played by environmental factors, AMD is more difficult to be modelled in mice. Furthermore, mice do not possess a welldefined macula, which is particularly affected in human AMD. Notwithstanding, it is possible to mimic some forms of AMD, as well as juvenile inherited forms of macular degeneration, using knock-out or transgenic mouse models (reviewed in Elizabeth Rakoczy et al., 2006; Fletcher et al., 2011). Stargardt's disease is a juvenile inherited form of macular degeneration, where defects in lipid biosynthesis and transport occur (reviewed in Molday and Zhang, 2010). $A B C R$ (a member of $A B C$ transporter family) null mice are used to mimic recessive form of Stargardt's disease while transgenic mice expressing the human mutant form of ELOVL4 (an enzyme that catalyzes the elongation of very long-chain fatty acids) mimic the autosomal dominant Stargardt-like disease (Karan et al., 2005; Weng et al., 1999). In both the mutant mice, accumulation of lipofuscin granules in RPE is observed and is correlated with photoreceptor loss. Indeed, lipofuscin accumulation is one of the hallmarks of several forms of macular degeneration. The studies of these mice allowed to hypothesize that accumulation of lipofuscin (and its main component, the fluorophore A2E) into RPE cells would result in toxicity and death of these cells, with deleterious secondary consequences on photoreceptors. 
Knock-in mice expressing a mutated form (W93C) of Bestrophin anion channel revealed to be a good model of the inherited form of macular degeneration, BVMD (Best vitelliform macular dystrophy, Zhang et al., 2010). The aminoacid substitution present in this mutated protein exerts a dominant negative effect on the channel activity. Indeed, these mice developed several features typical of BVMD, like retinal detachment in central region of the eye, accumulation of debris like shed outer segment, lipofuscin and lipid droplets. Furthermore, calcium signalling was suppressed in the transgenic mice. Such findings suggest that calcium may play a pivotal role in the pathogenesis of BVMD. Furthermore, since BVMD is the second cause of juvenile inherited macular degeneration (following Stargardt's disease), their use is thought to generate important data for therapeutical approaches. Other models, like mice lacking monocyte chemoattractant protein-1 (Ccl-2) or its cognate C-C chemokine receptor-2 (Ccr-2) also develop characteristic features of AMD, like drusen, lipofuscin accumulation and choroidal neo-vascularization (CNV), as well as photoreceptor degeneration (Ambati et al., 2003). Importantly, choroidal macrophage recruitment was impaired in $\mathrm{Ccl}-2-/-$ and $\mathrm{Ccr}-2 \%$, leading to accumulation of complement C5a and IgG proteins. This accumulation, in turn, leads to overexpression of vascular endothelial growth factor (VEGF) by RPE, likely mediating the CNV phenotype. Other interesting factors have been shown to play a role in RPE degeneration and development of particular forms of AMD. Mice lacking functional Dicer1 in the RPE, for example, develop

\section{Mouse models for RP}

\begin{tabular}{llll}
\hline Affected proteins & Affected genes & Inheritance & Phenotype \\
\hline $\begin{array}{l}\text { Rod visual pigment } \\
\begin{array}{l}\text { Phototransduction } \\
\text { proteins }\end{array}\end{array}$ & Rhodopsin & $\begin{array}{l}\text { Autosomal } \\
\text { dominant }\end{array}$ & $\begin{array}{l}\text { Defects in Rhodopsin sorting, glycosilation } \\
\text { and/or folding, resulting in cell toxicity }\end{array}$ \\
$\begin{array}{llll}\text { Structural proteins } \\
\text { PRPH }\end{array}$ & Recessive & $\begin{array}{l}\text { High cGMP and calcium levels, determining } \\
\text { cell death }\end{array}$ \\
Ciliary proteins & $R P 1$ & $\begin{array}{l}\text { Autosomal } \\
\text { dominant } \\
\text { X-linked }\end{array}$ & $\begin{array}{l}\text { Rod outer discs abnormalities, leading to } \\
\text { photoreceptor death }\end{array}$ \\
\hline $\begin{array}{l}\text { Autosomal } \\
\text { dominant }\end{array}$ & $\begin{array}{l}\text { Defects in disc membrane organization and } \\
\text { protein sorting/localization, leading to cell } \\
\text { death }\end{array}$ \\
\hline
\end{tabular}

\section{Mouse models for AMD}

\begin{tabular}{lll}
\hline Disease category & $\begin{array}{l}\text { Affected } \\
\text { genes }\end{array}$ & Phenotype \\
\hline $\begin{array}{l}\text { Juvenile inherited forms } \\
\text { of macular degeneration }\end{array}$ & $\begin{array}{l}\text { ABCR, } \\
\text { ELOVL4, } \\
\text { Bestrophin }\end{array}$ & Lipofuscin accumulation, resulting in RPE degeneration \\
$\begin{array}{l}\text { Dry AMD (geographic } \\
\text { atrophy) }\end{array}$ & $\begin{array}{l}\text { Dicer1 } \\
\text { AMD (general features) }\end{array}$ & $\begin{array}{l}\text { Accumulation of Alu RNAs, which results in RPE cell } \\
\text { dismorphology and death }\end{array}$ \\
\hline
\end{tabular}

Table 1. Main mouse models for RP or AMD, discussed in the present manuscript. 
RPE dysmorphology similar to those observed in humans affected by geographic atrophy (or dry AMD) and RPE degeneration (Kaneko et al., 2011). Importantly, Dicer1 depletion in RPE results in increased levels of Alu RNAs, which are responsible for the cell death. Thus, a variety of different mechanisms appear to be involved in different steps, or forms, of AMD.

\subsubsection{Mouse models and therapies for retina degeneration}

The plethora of data obtained from the studies on mouse models has provided potential targets of pharmaceutical interest. Some $\mathrm{Ca}^{2+}$ channel blockers were found to efficiently protect photoreceptor of $r d 1$ mice from degeneration. For example D-cis-diltiazem, a cGMPgated channel blocker used to treat cardiac disfunctions, was shown to slow down photoreceptor degeneration and to preserve visual function in $r d 1$ mice (Frasson et al., 1999). More recently, similar observations were extended to other calcium channel blockers, able to preserve photoreceptor viability in mouse models for retinal degeneration (Takano et al., 2004). These results confirm cGMP-gated channels as important pharmacological targets for treating some forms of RP, like PDE6B recessive RP. Other factors play an important role in preserving photoreceptor viability. For example, cytotoxicity in $\mathrm{P} 23 \mathrm{H}$ mutant mice was exacerbated by lack of 11-cis-retinal chromophore, thus indicating an important role for this molecule in protecting from P23H-induced cell death(Sakami et al., 2011). Indeed, pharmacological replacement of 11-cis-retinal (as well as other retinoids) showed beneficial effects in the treatment of several forms of retina degeneration (Palczewski, 2010). Proteins may be also used to treat retina degeneration. It was shown that injection of rod-derived cone viability factor (RdCVF), a protein secreted by rod cells, is able to protect cone cells from death in $r d 1$ mice (Leveillard et al., 2004). This observation is particularly important, since cones affection in late stages of RP is responsible for legal blindness. Thus, due to its ability to maintain cones viable and to preserve their function, future therapeutic strategies in humans should consider the possibility to deliver RdCVF protein in the patients' retina, or to promote its expression from unaffected cells (Leveillard and Sahel, 2010). Besides RdCVF, systemic administration of Insulin in $r d 1$ mice increased the rate of cone survival (Punzo et al., 2009). It is evident that different therapeutic strategies are becoming available to promote photoreceptor maintenance.

However, drug or molecule treatment is not the only strategy that can be used for this aim. Gene therapy, for example, showed promising results in treating some forms of RP in mouse models. Indeed, adeno-associated virus serotype 5 (AAV5) has been recently used to deliver mouse rhodopsin in $\mathrm{P} 23 \mathrm{H}$ transgenic mice (Mao et al., 2011). These mice (which mimic autosomal dominant RP) showed significant rescue of photoreceptor function (assessed by electroretinogram recording) as well as photoreceptor viability. Although it is still not known how wild type rhodopsin rescues the dominant effect of mutated rhodopsin, this result is encouraging in the view of gene therapy treatment of human RP. Several clinical trials have shown to be effective in improving visual function in patients affected by Leber's congenital amaurosis (a recessive retinal degeneration) (Bainbridge et al., 2008; Simonelli et al., 2010). Thus, delivery of functional rhodopsin could represent a valid option for treating RP. However, since high rhodopsin levels can result in toxicity for rod cells, much work is still required to optimize these therapies in humans. Recently, adenoassociated vectors were used to deliver human RPGRIP1 gene in mouse models of Leber's congenital amaurosis (Pawlyk et al., 2010). Expression of RPGRIP1 was able to improve rod and cone survival in the retina of these mice. 
Different approaches have been designed to treat also AMD. Importantly, many of these approaches have been designed to target wet (exudative) AMD (reviewed in Querques et al., 2011). As we have seen, one of the hallmarks of wet AMD is the process of neovascularization, which is correlated to severe visual loss. To this regard, several strategies aim to block the process of blood vessel formation, to minimize the effects of macular degeneration. Indeed, antibodies against the angiogenic factor VEGF, like Ranibizumab, have demonstrated successful in blocking VEGF-dependent angiogenesis in patients affected by AMD, improving their visual functions (for a review, see Lien and Lowman, 2008). Not all the antibodies against VEGF are able to efficiently penetrate the retina, and some of them show important side-effects. Thus, AAV-assisted gene therapy seems to be a valid alternative to this approach. In particular, AAV2-mediated intravitreal delivery of chimeric forms of VEGF receptor Flt-1 showed promising results in mouse models (Pechan et al., 2009). In these oxygen-induced retinopathy models, the AAVdelivered chimeric proteins were able to inhibit efficiently angiogenesis, showing no detectable signs of toxicity. Thus, these results show promising candidate molecules for the treatment of human AMD by gene therapy.

Despite the abundance of strategies to target wet AMD, no therapies are available for treating dry or atrophic AMD (Querques et al., 2011). However, a recent study shows a potential and important therapeutic target. As seen above, Alu RNAs were shown to induce cytotoxicity in murine RPE cells, which developed a degeneration phenotype similar to atrophic AMD (Kaneko et al., 2011). Notably, subretinal administration of antisense oligonucleotides, which targeted and reduced Alu RNAs, inhibited efficiently the degeneration phenotype in vivo (Kaneko et al., 2011). Thus, this study reveals a promising target for blocking RPE degeneration typical of AMD. Inherited forms of macular degeneration are also current targets of therapeutic treatment. For example, administration of vitamin A to murine models of Stargardt's disease was shown to efficiently decrease the accumulation of lipofuscin, and to improve visual function (Ma et al., 2010). In a different approach, lentiviral-mediated delivery of human ABCA4 gene in Abca4\% mice showed effective reduction in the accumulation of the lipofuscin pigment A2E (Kong et al., 2008). Thus, gene therapy could also be used to treat genetic forms of macular degeneration.

\subsection{Alternative models for retina degeneration}

Besides the mouse models reported above, other mammalian animal models are used to get insights into the pathogenesis of inherited retina degeneration, such as rat, dog or pig. However, because the development of the retina and its morphology are remarkably conserved in all vertebrates, non-mammalian species have also emerged during the last decade as alternative valuable models. In particular, zebrafish, which is well suited for large-scale genetic screens, revealed to be very informative in the elucidation of the processes underlying retina degeneration (reviewed in Bibliowicz et al., 2011; Brockerhoff and Fadool, 2011; Li et al., 2010). Its importance is strengthened by the fact that not all the murine models are suitable to mimic a particular pathological feature or for the development of pharmacological therapies. In zebrafish, a dozen different genetic lesions have been identified leading to photoreceptor cell death, belonging to different functional classes. For example, mutation in the gene encoding the cone specific phosphodiesterase c 6 (pde6c) was shown to induce cone cell death, similarly to pde6b-induced rod cell death in mouse models (Stearns et al., 2007). Importantly, some rod cells also died in these mutant 
fish, primarily in areas where rod density was low. This result suggests an important correlation between secondary cell death and cell density. Another recent study taking advantage of zebrafish as a model system provided novel insights into the pathogenic potential of disease-associated mutations in RPGR (Ghosh et al., 2010).

The frog Xenopus laevis also recently revealed important in deciphering the mechanisms underlying photoreceptor degeneration (Tam and Moritz, 2006; Tam and Moritz, 2007; Tam and Moritz, 2009; Tam et al., 2006; Zhang et al., 2008). For example, transgenic frogs expressing different glycosylation-deficient forms of rhodopsin showed rod degeneration when rhodopsin glycosylation was inhibited in position N15 (Tam and Moritz, 2009). Strikingly, the photoreceptor degeneration was exacerbated when the frogs were exposed to light, while was attenuated in dark-reared animals. This result suggests that glycosylation is involved in rhodopsin stabilization, particularly after its activation by light. Studies on Xenopus also showed that the localization of rhodopsin is important for photoreceptor viability. In fact, in transgenic frogs expressing a rhodopsin bearing C-terminal truncation (Q350Ter), mutant rhodopsin (but not wild type endogenous rhodopsin) failed to correctly localize and induced a severe form of photoreceptor degeneration (Tam et al., 2006). Importantly, in this case degeneration occurred even in the dark, indicating that the toxic effects of mislocalized rhodopsin were independent from its activation. Additionally, since Xenopus retina contains numerous cone cells (differently from mice) this system would allow to examine more easily the secondary effects of rod death on cone viability.

\section{Studying retina regeneration in vivo}

The animal models described so far have greatly contributed to the understanding of mechanistic processes of retina degeneration. Furthermore, as we have seen, this knowledge has revealed instrumental in the excogitation of valid medical approaches. However, even though the available therapies lead to amelioration of the degeneration, these treatments cannot compensate for the cells that have been already lost, often limiting their efficacy to the early steps of the pathology. In order to compensate for this limitation, regenerative medicine aims at developing treatments that improve, or even induce, regeneration of lost cells, a process that involves formation of newly born cells, which then differentiate to replace dead cells.

In order to identify mechanisms and molecules that mediate retina regeneration, it is opportune to work with suitable animal models. The mouse models reported in the last section are not appropriate for deep examination of regenerative processes. One reason is that higher vertebrates show little regenerative potential. Moreover, the transgenic, knockout or natural mutant models presented above do not offer the possibility to control experimentally the duration of degeneration. Such a requisite is essential to observe the mechanisms acting during regeneration: first, one would induce degeneration of a particular retinal cell type; then, by blocking the degenerative processes, it would be possible to allow the regeneration to occur. This system would offer the possibility to study genes and pathways regulating regeneration.

Thus, the first problematic is the choice of the animal model. Amphibians such as frogs and salamanders, and fishes show a strong regenerative potential, maintained for a great part of their life. Importantly, it seems that part of the regenerative program active in lower vertebrates is still present in higher vertebrates like birds and mammalian, which show a limited and short regenerative response upon injuries (reviewed in Karl and Reh, 2010). 
Thus, the complete understanding of the regenerative program in fish and frogs would provide a basis in designing effective strategies able to stimulate or enhance this process in humans affected by degenerative retinopathies.

The second problematic is how to induce and to reverse the process of retina degeneration. Several methods can be employed to this aim: for example, it is possible to induce the death of photoreceptor (both rods and cones) by exposing dark-adapted animals to strong white light (Reme et al., 1995; Vihtelic and Hyde, 2000), or by using laser to mediate cell ablation (Wu et al., 2001). Small molecules can also be used to destroy retina cell types: mature photoreceptors are particular sensitive to N-Methyl-N-nitrosourea (MNU) (Tsubura et al., 2011), while exposure to high level of glutamate can induce death of retinal ganglion cells (RGCs), a finding that has been linked to several cases of glaucoma (Dreyer et al., 1996). Neurotoxins like ouabain can also be used to damage RGCs and cells of the inner nuclear layer (Fimbel et al., 2007; Sherpa et al., 2008). Logically, removing the drug or switching off the light source would block the degenerative event, allowing the system to recover and to regenerate. Finally, surgical methods can also be employed to remove small part of the retina, for example by cutting a portion of retina with a surgical blade or by pricking it with a needle (Cameron, 2000; Fausett and Goldman, 2006; Goldsmith and Harris, 2003; Vergara and Del Rio-Tsonis, 2009; Yoshii et al., 2007).

Although these strategies do not resemble generally a particular pathway occurring during human retina degenerative diseases, they offer the important advantage of controlling the timing and duration of degenerative treatment. However, the systems here described present also a limitation: for example light can be used to kill only photoreceptors, while chemicals or physical damage may lack enough specificity, affecting more than a particular cell type. Thus, in the recent years more elegant and fine tuned systems have been developed, like transgenic animals expressing an inducible and reversible cytotoxic gene under control of a retina specific promoter. Below, we will give examples of transgenic animal models which are thought to bring great contribution to the study of regeneration.

\subsection{Transgenic models for regeneration studies}

Transgenic animals offer the unique possibility to selectively induce cell death (provided that a cell or tissue specific promoter is available) through the use of a cytotoxic gene whose activity is inducible and reversible. One powerful and elegant system to induce specific cell ablation in fish and frogs, in an inducible and reversible fashion, is the nitroreductase/metronidazole (NTR/mtz) system (Figure 1). Bacterial NTR is a flavoprotein enzyme able to reduce nitro group-containing substrates. When a non-toxic molecule like mtz (prodrug), is reduced by NTR, it is converted into a powerful DNA cross-linker agent leading to cell death by apoptotic mechanisms. Thus, mtz can be added into the water of animals expressing NTR under the regulation of a cell-specific promoter to induce cell death only in those cells expressing the enzyme. Cells not expressing NTR are not directly affected by the prodrug $\mathrm{mtz}$, validating the high specificity of the system. Subsequently, mtz can be removed by washing the transgenic animals in mtz-free water, allowing the study of the cellular and molecular processes of regeneration (Curado et al., 2007; Curado et al., 2008; Davison et al., 2007; Pisharath, 2007; Pisharath et al., 2007).

In the context of the retina, NTR/mtz system has been used to induce cell death successfully in different retina cells of zebrafish and Xenopus laevis, using enhancer traps or specific promoters (Choi et al., 2011; Montgomery et al., 2010; Zhao et al., 2009). In particular, 


\section{A}
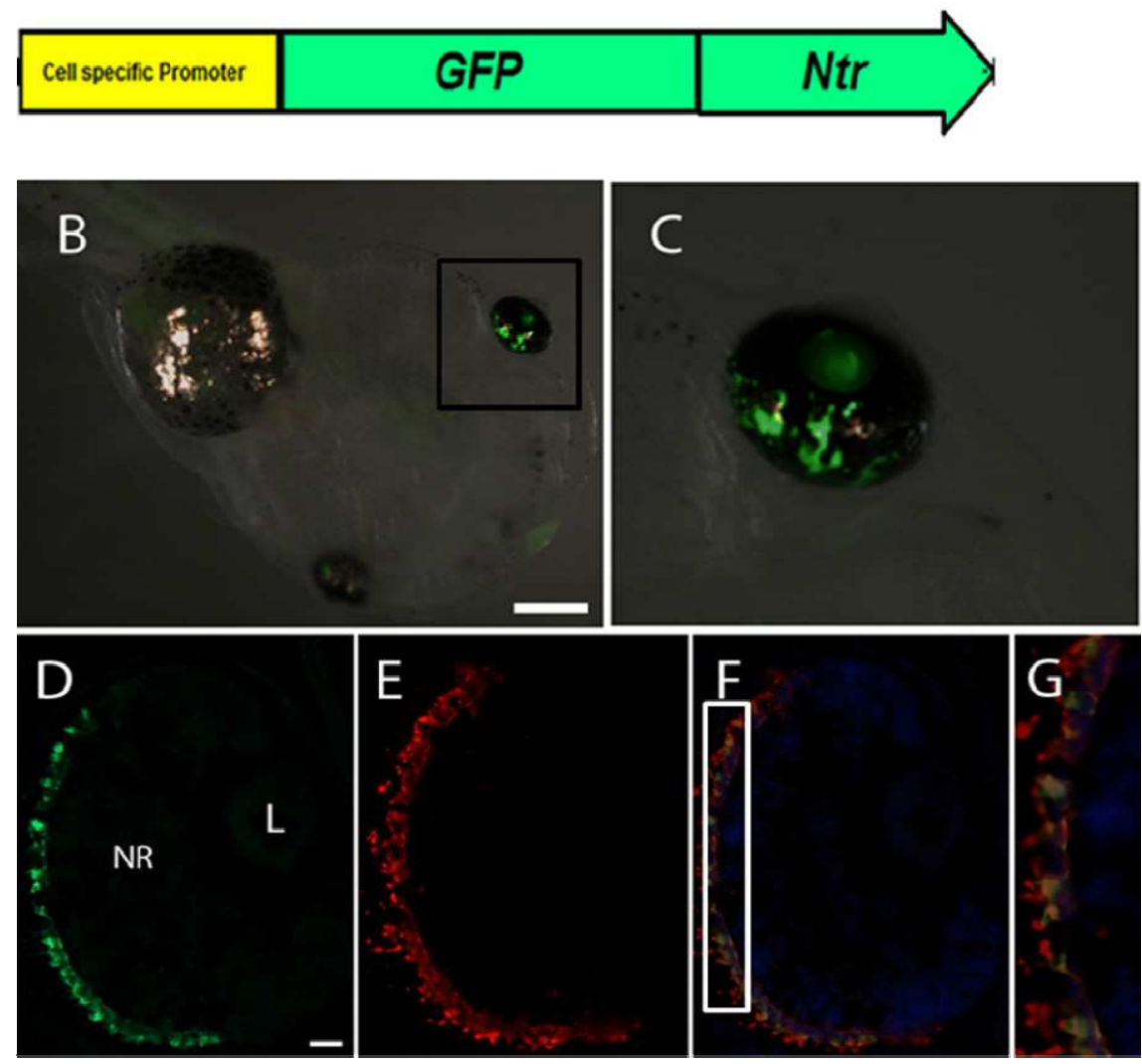

A: Schematic diagram representing a chimeric GFP-tagged NTR under the control of a specific promoter. This construct is used to create transgenic frogs. B: Ventral view of a stage 41 transgenic tadpole carrying a GFP-NTR transgene under the control of the rod specific Xop promoter. C: Magnification of the onset shown in B, showing GFP fluorescence in the eye. D-F: Transversal retinal section of such a transgenic tadpole, following anti-GFP (green, D) and anti-rhodopsin (red, E) immunostaining. The merge image $(\mathrm{F})$ confirms the rod specificity of expression. G: magnification of the onset shown in F. $1=$ lens; $n r=$ neural retina. Scale bar in $B=2 \mathrm{~mm}$, scale bar in $\mathrm{D}=20 \mu \mathrm{m}$.

Fig. 1. The NTR/mtz transgenic system in frogs.

transgenic Xenopus frogs were obtained, expressing NTR under the control of rhodopsin promoter (Xop::NTR). This model is of particular importance, since it mimics human RP. Indeed, when tadpoles at stage 50 were exposed to $\mathrm{mtz}$, their rods started to die soon after the treatment. Furthermore, when $\mathrm{mtz}$ treatment was prolonged, cone degeneration was also observed following rod cell death, a characteristic of RP (Choi et al., 2011). Importantly, upon mtz removal, newly born rods were observed in a time-range of thirty days, indicating successful regeneration of death cells. Regeneration studies were conducted also in zebrafish retina, where rod or bipolar cells were targeted for ablation. Again, treatment with mtz induced specific ablation of NTR-expressing cells, while removal of the prodrug allowed 
regeneration of rods and bipolar interneurons in a short period (Montgomery et al., 2010; Zhao et al., 2009). Altogether, these data show that the NTR/mtz system is a powerful tool to induce cell-death in a specific and reversible fashion, which can be applied to animals with regenerative capacity to investigate the molecular pathways governing the phenomenon of regeneration.

Other cytotoxic genes can also be used to achieve retinal cell death. For example, an inducible form of caspase-9 (iCasp9) was expressed in Xenopus rod photoreceptors by using rhodopsin promoter (Hamm et al., 2009). This inducible caspase is activated by the drug AP20187, added to the tadpoles' medium, thus leading to death of rod cells. Similarly to $\mathrm{mtz}$, AP20187 can be removed at any time, thus switching off the stimulus for rod death. These frogs developed abnormalities in the function of cone cells, assessed by electroretinogram. Importantly, cone functionality was restored 6 months after the treatment, confirming the reversibility of this model. However, differently from the Xop::NTR Xenopus model, no clear signs of cone apoptosis were observed, although the reasons of this difference are not known. In conclusion, different systems can be employed to induce death of specific cell types, enabling the study of their regeneration and the secondary consequences related to their death on neighbouring tissues.

\subsection{Sources of regeneration}

In order to understand the retina regenerative process, the first question to answer is which cells are able to set off the regeneration? Although mammals are devoid of a regenerative capacity, they possess cells with stemness features in the ciliary body, a structure derived from the optic cup, lying between the retina and the iris. Although these cells remain mitotically quiescent in vivo, they are able to clonally expand in vitro (Ahmad et al., 2000; Coles et al., 2004; Tropepe et al., 2000). Although the proliferative and differentiation potential of such ciliary body-derived cells towards the photoreceptor lineage is controversial (Cicero et al., 2009; reviewed in Locker et al., 2010), this raises the question whether and how it is possible to stimulate the proliferative and differentiation ability of these cells in vivo, to regenerate injured cells. Lower vertebrates on the other hand possess a region, adjacent to ciliary body, called ciliary marginal zone (CMZ), where active proliferating retinal stem and progenitor cells reside. These cells, capable of generating all types of retinal neuron and glial cells, contribute to the perpetually expanding retina of these animals, which grow throughout life (reviewed in Otteson and Hitchcock, 2003; Wetts and Fraser, 1988; Wetts et al., 1989). CMZ cells were shown to contribute to the replacement of retinal cells after injury (reviewed in Locker et al., 2009; Locker et al., 2010; Moshiri et al., 2004). However, it seems that the origin of regenerating cells can be species-specific and changes according to the developmental stage.

\subsubsection{CMZ and RPE as a source of retina regeneration}

If retina is surgically removed in urodele amphibians, like salamanders, RPE cells respond to injury by re-entering the cell cycle. These cells undergo a process of transdifferentiation, loosing features of differentiated RPE like their pigmentation, and form a new (inner) layer which will give rise to a complete retina, with normal lamination and apparently functional (Araki, 2007). In the anuran amphibian Xenopus, both stem cells of the CMZ and cells constituting the RPE are able to regenerate the injured retina. The contribution of CMZ in Xenopus retina regeneration was already known since 1982 (Mitashov and Maliovanova, 
1982). When neural retina was removed, partial regeneration of neural retina was observed by proliferating stem cells normally present in the CMZ. However, it was also shown that, upon surgical retinectomy, cells of RPE delaminated and migrate toward the retinal vascular membrane (RVM), forming a new layer (Yoshii et al., 2007). The cells of this layer transdifferentiate, as assessed by expression of neural retina markers. Importantly, the pigmented cells were intermingled with other cells deriving from the CMZ, which also contributed to the newly formed neural retina. This study suggested also a role for RVM in the process of regeneration, which could be fundamental. Although the molecular nature of RVM contribution in regeneration remains still elusive, it could act likely through the secretion of particular growth factors into extracellular matrix. Indeed a possible role for this tissue in retina regeneration was observed already in 1987 in a study on the amphibian Rana catesbienna, where close contact between RVM and delaminated RPE was observed (Reh and Nagy, 1987). Its importance is also underlined by the fact that, when absent, the neural retina is not able to regenerate. When neural retina was surgically removed, together with the RVM, no regeneration occurred in tadpoles, unless specific growth factors were added to the operated eyes (Vergara and Del Rio-Tsonis, 2009). Further work is required in order to fully elucidate the modalities through which RVM act during regeneration. It is important to note, at this point, that the mechanisms of regeneration observed in amphibians are also present in higher vertebrates such as chicken, although this potential is limited to a short temporal window. The hatched chicken retina indeed also possesses a CMZ, although with a more limited potential compared to that of fish and amphibians (Fischer and Reh, 2000). Thus, both RPE and stem cells residing in the ciliary body/CMZ are able to contribute to retinal regeneration, until approximately embryonic day 4.5 (E4.5) (reviewed in Spence et al., 2007b).

\subsubsection{Müller glia as a source of retina regeneration}

$\mathrm{RPE}$ and CMZ are not the only origin of regeneration. Müller glia were also shown to display neurogenic capacity and to contribute to the regenerative process following retinal injury in diverse vertebrate retinas (Bernardos et al., 2007; Das et al., 2006; Fausett and Goldman, 2006; Fischer and Reh, 2001; Fischer and Reh, 2003; Monnin et al., 2007; Yurco and Cameron, 2005). For instance, upon photoreceptor cell death in transgenic zebrafish expressing NTR in rod cells, Müller cells were observed to re-enter the cell cycle. This yielded clusters of neural progenitor cells, which later on differentiated in rod cells (Montgomery et al., 2010). It is important to note, however, that Müller glia was mobilized only when the damage to rod cells was extensive: when mosaic transgenic lines, expressing NTR only in a small subset of rods, were treated with mtz to induce cell death, only specialized Müller glia-derived progenitors committed to rod lineage (known as rod precursor cells) were activated for regeneration. This result demonstrates that factors, like the extent of damage, can influence the source of regeneration. The role of Müller glia in regeneration has been observed in other studies. Upon light damage in zebrafish, Müller glia cells re-enter the cell cycle and de-differentiate, as judged by the loss of specific differentiation markers such as GFAP (glial fibrillary acidic protein) and Glutamine Synthetase. Successively, these cells start to express neural marker such as Pax6, and form neurogenic clusters that migrate toward the outer nuclear layer, where photoreceptors reside (Thummel et al., 2008a). In particular, ability of glial cells to re-enter the cell cycle is fundamental for the regeneration. Indeed, inhibition of Müller glia division, by knock-down 
of PCNA (proliferating cell nuclear antigen), inhibited proliferation and expression of neural markers such as Pax6 (Thummel et al., 2008b). This resulted in failure to regenerate photoreceptors in zebrafish light-damaged retinas confirming that Müller glia, upon proliferation, can serve as a major source of retinal regeneration. Importantly, lineage tracing experiments indicate that Müller glia can regenerate all retinal cell types, demonstrating the high plasticity of these cells (Ramachandran et al., 2010b). However, the neurogenic potential of activated Müller glia seems to be limited, as particular mature retinal cell types are rarely or never regenerated following injury (Fischer and Reh, 2001; Ooto et al., 2004). Nonetheless, this can be experimentally overcome by treatment with specific soluble factors (Ooto et al., 2004; Osakada et al., 2007) raising the possibility that Müller glia could be stimulated to produce specific retinal cell types, provided exogenous supply of endogenously limiting factors.

What initiates the regenerative response of Müller glia? This question remains still largely unanswered, however a fascinating hypothesis points to its role in phagocytosis of dead photoreceptors. Interestingly, it was observed that Müller cells were able to engulf apoptotic bodies derived from light-damaged photoreceptors. Upon phagocytosis of dead cells, it was reported that Müller glia started to proliferate, as assessed by PCNA immunolabelling, and successively regenerated dead cells (Bailey et al., 2010). On the other hand, when phagocytosis was blocked by means of inhibitors, the process of regeneration failed to occur. In mammalian retina, Müller glia can be activated in response to injury, becoming hypertrophic. However, very few cells enter the cell cycle (Bringmann et al., 2009). Thus, understanding the signals that activate these cells toward a regeneration program is a necessary step to successfully induce retinal regeneration in mammals.

\subsection{Candidate genes and signaling pathways involved in regeneration}

In the previous section, we have discussed about the sources of regeneration in lower vertebrates, identifying the RPE, the CMZ and the Müller glia as the main generator of regeneration. What are the molecular signals that activate these cells in response to retina injury? To date, a network of different genes and signaling has been shown to act during regeneration. An important goal of regenerative medicine is to characterize the network in fine details, so that this knowledge can be used to promote retinal regeneration in patients affected by retinopathies.

\subsubsection{Transcription factors promoting regeneration}

Several transcription factors involved in early retinogenesis were shown to be essential for regeneration to occur. It has been recently reported in Xenopus tadpoles that the transcription factor $R x 1$, a paired like homeobox gene fundamental for early eye field specification, plays a central role in retinal regeneration (Martinez-De Luna et al., 2011). When retina was physically damaged, retinal progenitor cells were found to migrate near the site of wound and to initiate regeneration of the entire damaged retina. However, when $R x 1$ was knocked-down by means of small hairpin RNA (shRNA), defects in morphology of progenitor cells were observed, together with a reduced expression of progenitor markers. Examples of transcription factors acting during Müller glia-dependant regeneration come from studies in zebrafish. Indeed, the proneural transcription factor Ascl1 is essential for the regeneration process in the fish (Ramachandran et al., 2010a). Ascl1 mRNA is rapidly induced in dedifferentiating Müller glia, and it is necessary for the transcription of the 
pluripotency RNA binding protein Lin-28. Lin-28, on its turn, inhibits the biogenesis of Let-7, a miRNA associated with the repression of regeneration-associated genes including Ascl 1 itself, hspd1 and Pax6b. Thus, while normally Let-7 is implicated in maintaining the differentiation status of Müller glia, its Ascl1/Lin28-mediated downregulation in response to injury is a pre-requisite for the re-entry in the cell cycle and dedifferentiation of the glial cells. The activity of Pax6a and Pax6b transcription factors is also essential for the division of the glia-derived neuronal progenitors. Both genes are expressed in Müller glia soon after the retinal damage (Raymond et al., 2006). Their knockdown in zebrafish reduced the number of inner nuclear layer proliferating neuronal progenitors, resulting in a corresponding loss of regenerated photoreceptors (Thummel et al., 2010). Pax6 was also shown to be sufficient, upon ectopic expression, to promote transdifferentiation of the RPE in the chick retina both during development (Azuma et al., 2005) and during the regenerative process (Spence et al., 2007c). Due to their involvement in early retinal development, where such transcription factors regulate proliferation and specification of early retinal progenitors, it is plausible that they play an analogous role on the regenerating cells during the process of regeneration. However, such hypothesis remains to be tested and the details by which these factors act remain to be identified.

\subsubsection{Signaling molecules involved in regeneration}

To discover novel factors involved in retina regeneration, transcriptional profiles of injuryactivated Müller glial cells were generated from adult zebrafish, at the early stages of photoreceptor regeneration (Qin et al., 2009). The chaperone hspd1 and the mitotic checkpoint kinase mps1 were shown to be up-regulated in these cells. Subsequent functional analyses indicated that both factors are required for cone regeneration, at different steps of the process (Qin et al., 2009). Although the mutation in these genes was shown to inhibit neurogenic cluster formation and neuronal progenitor proliferation, the exact mechanisms underlying their activities remain unknown. Such genes, activated during regeneration play an obvious important role, yet they represent a downstream response to the initial event that damages the retina. This implies that there must be one or more signals that initiate the regeneration process. So far, several signaling molecules have been identified, which might play such a role. It is long known that the FGF (fibroblast growth factor) pathway is a critical inductive cue for retinal regeneration. Basic FGF-2 was indeed shown to induce RPE transdifferentiation in chick (Park and Hollenberg, 1989; Park and Hollenberg, 1991) and Xenopus (Sakaguchi et al., 1997). The importance of FGF-2 in Xenopus regeneration was confirmed also recently. Indeed, administration of FGF-2 was able to stimulate regeneration of a new entire retina in Xenopus tadpoles, where complete neural retina (and vascular membrane) was surgically removed (Vergara and Del Rio-Tsonis, 2009). Inhibition of the MAPK pathway reduced significantly the regeneration, highlighting its importance in retina regeneration. MAPK may regulate retina regeneration also in birds. For instance, overexpression of a constitutively active form of MAPK (Mek-1) in the chick embryonic retina induced RPE transdifferentiation into neural retina, an event correlated with downregulation of the RPE-specific marker Mitf, and overexpression of Pax6 (Galy et al., 2002; Spence et al., 2007c). Among other critical factors, CNTF (ciliary neurotrophic tactor) was observed to stimulate Müller glia proliferation in zebrafish (Kassen et al., 2009) and BMP signaling was shown to regulate regeneration from the ciliary margin in chick, through Smad activation and upregulation of FGF/MAPK pathway (Haynes et al., 2007). Besides, Sonic hedgehog (Shh) also plays a key role in chick retina regeneration. In particular, 
exogenous activation of Shh in cooperation with FGF activation induces regeneration from the ciliary body, by stimulating the proliferation of the cells residing in this region (Spence et al., 2007a; Spence et al., 2004). More importantly, it was observed that activation of analogous pathways were able to initiate retina regeneration even in mammals. The mammalian optic nerve does not regenerate when injured. However, significant regeneration can be achieved through exogenous administration of various growth factors. For example, intravitreous injections of CTNF strongly induced optic nerve regeneration in rats where the optic nerve was cut (axotomy). This effect was shown to strongly rely on MAPK activity, since inhibition of MAPK compromised the effects of CNTF on neurite outgrowth (Muller et al., 2009). Similarly, simultaneous administration of CNTF and inhibition of Rho kinase (Rock) promoted retinal ganglion cell survival and regeneration upon axotomy (Lingor et al., 2008). Hedgehog signaling could also represent a potential candidate pathway to stimulate mouse retina regeneration. Activation of Shh pathway in patched $^{+-}\left(\mathrm{ptc}^{+/}\right)$mice results in persistent proliferating progenitors at the ciliary margin, resembling the CMZ of lower vertebrates. Importantly, such patched mutation in $\mathrm{P} 23 \mathrm{H}$ mice was able to promote a partial rescue of the retina degeneration (Moshiri et al., 2004).

The factors shown here are only some of the many known to be involved or stimulate retina regeneration. Although the list of these factors is in continuous expansion, our knowledge about their in vivo function modalities is still modest. The most important point emerging from the present data is that the mechanisms regulating regeneration seem to be conserved among vertebrates. In particular, there are some evidences that factors normally regulating regeneration in lower vertebrates can be successfully used to improve regeneration in higher vertebrates like birds and mammals. Thus, an interesting scenario emerges from these results: once a particular factor is identified to have a role during retina regeneration in animals showing regeneration, then it is important to test whether this factor is conserved in mammals and whether it has any ability to stimulate retina regeneration.

\section{Conclusion}

The promise of regenerative medicine is to induce regeneration of damaged tissues or entire complex structures in situ. Although mammalian possess a natural regenerative capacity, this is very limited and restricted to a few tissues, such as the liver and the skin. On the other hand, amphibians and fishes have extensive regenerative capacity. Concerning the retina, they are able to regenerate all the neurons and the glia of this fundamental tissue. Understanding precisely all the molecules and genes involved in this process, as well as the network of interactions that these form in vivo will be fundamental for a rationale screening of pharmacological drugs, able to trigger the precise regenerative process. Furthermore, the lower vertebrates adopt mechanisms, such as transdifferentiation and dedifferentiation, which mammalian does not seem to possess. In the next future, it will be important to determine exactly how Müller glia or RPE exploit these processes to regenerate damaged tissues, so that we could use them to initiate regeneration directly in vivo, in patients affected by degenerative retinopathies.

\section{Acknowledgments}

This work is supported by grants from the CNRS, University Paris Sud, ARC, Retina France, ANR and Région Île de France (AMBRe network). G.C. is a AMBRe network fellow. We thank A. Chesneau for his technical support to make Xenopus transgenics shown in Figure 1. 


\section{References}

Ahmad, I., Tang, L. and Pham, H. (2000). Identification of neural progenitors in the adult mammalian eye. Biochem Biophys Res Commun 270, 517-21.

Ambati, J., Anand, A., Fernandez, S., Sakurai, E., Lynn, B. C., Kuziel, W. A., Rollins, B. J. and Ambati, B. K. (2003). An animal model of age-related macular degeneration in senescent Ccl-2- or Ccr-2-deficient mice. Nat Med 9, 1390-7.

Araki, M. (2007). Regeneration of the amphibian retina: role of tissue interaction and related signaling molecules on RPE transdifferentiation. Dev Growth Differ 49, 109-20.

Azuma, N., Tadokoro, K., Asaka, A., Yamada, M., Yamaguchi, Y., Handa, H., Matsushima, S., Watanabe, T., Kida, Y., Ogura, T. et al. (2005). Transdifferentiation of the retinal pigment epithelia to the neural retina by transfer of the Pax6 transcriptional factor. Hum Mol Genet 14, 1059-68.

Bailey, T. J., Fossum, S. L., Fimbel, S. M., Montgomery, J. E. and Hyde, D. R. (2010). The inhibitor of phagocytosis, O-phospho-L-serine, suppresses Muller glia proliferation and cone cell regeneration in the light-damaged zebrafish retina. Exp Eye Res 91, 601-12.

Bainbridge, J. W., Smith, A. J., Barker, S. S., Robbie, S., Henderson, R., Balaggan, K., Viswanathan, A., Holder, G. E., Stockman, A., Tyler, N. et al. (2008). Effect of gene therapy on visual function in Leber's congenital amaurosis. N Engl J Med 358, 22319.

Bernardos, R. L., Barthel, L. K., Meyers, J. R. and Raymond, P. A. (2007). Late-stage neuronal progenitors in the retina are radial Muller glia that function as retinal stem cells. $J$ Neurosci 27, 7028-40.

Berson, E. L. (1993). Retinitis pigmentosa. The Friedenwald Lecture. Invest Ophthalmol Vis Sci 34, 1659-76.

Bibliowicz, J., Tittle, R. K. and Gross, J. M. (2011). Toward a better understanding of human eye disease insights from the zebrafish, Danio rerio. Prog Mol Biol Transl Sci 100, 287-330.

Boon, C. J., den Hollander, A. I., Hoyng, C. B., Cremers, F. P., Klevering, B. J. and Keunen, J. E. (2008). The spectrum of retinal dystrophies caused by mutations in the peripherin/RDS gene. Prog Retin Eye Res 27, 213-35.

Bringmann, A., Iandiev, I., Pannicke, T., Wurm, A., Hollborn, M., Wiedemann, P., Osborne, N. N. and Reichenbach, A. (2009). Cellular signaling and factors involved in Muller cell gliosis: neuroprotective and detrimental effects. Prog Retin Eye Res 28, 423-51.

Brockerhoff, S. E. and Fadool, J. M. (2011). Genetics of photoreceptor degeneration and regeneration in zebrafish. Cell Mol Life Sci 68, 651-9.

Bull, N. D. and Martin, K. R. (2011). Towards Stem Cell-Based Therapies for Retinal Neurodegenerative Diseases. Stem Cells.

Cameron, D. A. (2000). Cellular proliferation and neurogenesis in the injured retina of adult zebrafish. Vis Neurosci 17, 789-97.

Chang, G. Q., Hao, Y. and Wong, F. (1993). Apoptosis: final common pathway of photoreceptor death in rd, rds, and rhodopsin mutant mice. Neuron 11, 595-605.

Choi, R. Y., Engbretson, G. A., Solessio, E. C., Jones, G. A., Coughlin, A., Aleksic, I. and Zuber, M. E. (2011). Cone degeneration following rod ablation in a reversible model of retinal degeneration. Invest Ophthalmol Vis Sci 52, 364-73. 
Cicero, S. A., Johnson, D., Reyntjens, S., Frase, S., Connell, S., Chow, L. M., Baker, S. J., Sorrentino, B. P. and Dyer, M. A. (2009). Cells previously identified as retinal stem cells are pigmented ciliary epithelial cells. Proc Natl Acad Sci U S A 106, 6685-90.

Coles, B. L., Angenieux, B., Inoue, T., Del Rio-Tsonis, K., Spence, J. R., McInnes, R. R., Arsenijevic, Y. and van der Kooy, D. (2004). Facile isolation and the characterization of human retinal stem cells. Proc Natl Acad Sci U S A 101, 15772-7.

Connell, G., Bascom, R., Molday, L., Reid, D., McInnes, R. R. and Molday, R. S. (1991). Photoreceptor peripherin is the normal product of the gene responsible for retinal degeneration in the rds mouse. Proc Natl Acad Sci U S A 88, 723-6.

Connell, G. J. and Molday, R. S. (1990). Molecular cloning, primary structure, and orientation of the vertebrate photoreceptor cell protein peripherin in the rod outer segment disk membrane. Biochemistry 29, 4691-8.

Curado, S., Anderson, R. M., Jungblut, B., Mumm, J., Schroeter, E. and Stainier, D. Y. (2007). Conditional targeted cell ablation in zebrafish: a new tool for regeneration studies. Dev Dyn 236, 1025-35.

Curado, S., Stainier, D. Y. and Anderson, R. M. (2008). Nitroreductase-mediated cell/tissue ablation in zebrafish: a spatially and temporally controlled ablation method with applications in developmental and regeneration studies. Nat Protoc 3, 948-54.

Dahlmann-Noor, A., Vijay, S., Jayaram, H., Limb, A. and Khaw, P. T. (2010). Current approaches and future prospects for stem cell rescue and regeneration of the retina and optic nerve. Can J Ophthalmol 45, 333-41.

Das, A. V., Mallya, K. B., Zhao, X., Ahmad, F., Bhattacharya, S., Thoreson, W. B., Hegde, G. V. and Ahmad, I. (2006). Neural stem cell properties of Muller glia in the mammalian retina: regulation by Notch and Wnt signaling. Dev Biol 299, 283-302.

Davison, J. M., Akitake, C. M., Goll, M. G., Rhee, J. M., Gosse, N., Baier, H., Halpern, M. E., Leach, S. D. and Parsons, M. J. (2007). Transactivation from Gal4-VP16 transgenic insertions for tissue-specific cell labeling and ablation in zebrafish. Dev Biol 304, 811-24.

Dreyer, E. B., Zurakowski, D., Schumer, R. A., Podos, S. M. and Lipton, S. A. (1996). Elevated glutamate levels in the vitreous body of humans and monkeys with glaucoma. Arch Ophthalmol 114, 299-305.

Dryja, T. P., McGee, T. L., Reichel, E., Hahn, L. B., Cowley, G. S., Yandell, D. W., Sandberg, M. A. and Berson, E. L. (1990). A point mutation of the rhodopsin gene in one form of retinitis pigmentosa. Nature 343, 364-6.

Elizabeth Rakoczy, P., Yu, M. J., Nusinowitz, S., Chang, B. and Heckenlively, J. R. (2006). Mouse models of age-related macular degeneration. Exp Eye Res 82, 741-52.

Farrar, G. J., Palfi, A. and O'Reilly, M. (2010). Gene therapeutic approaches for dominant retinopathies. Curr Gene Ther 10, 381-8.

Fausett, B. V. and Goldman, D. (2006). A role for alpha1 tubulin-expressing Muller glia in regeneration of the injured zebrafish retina. J Neurosci 26, 6303-13.

Fimbel, S. M., Montgomery, J. E., Burket, C. T. and Hyde, D. R. (2007). Regeneration of inner retinal neurons after intravitreal injection of ouabain in zebrafish. J Neurosci 27, 1712-24.

Fischer, A. J. and Reh, T. A. (2000). Identification of a proliferating marginal zone of retinal progenitors in postnatal chickens. Dev Biol 220, 197-210.

Fischer, A. J. and Reh, T. A. (2001). Muller glia are a potential source of neural regeneration in the postnatal chicken retina. Nat Neurosci 4, 247-52. 
Fischer, A. J. and Reh, T. A. (2003). Potential of Muller glia to become neurogenic retinal progenitor cells. Glia 43, 70-6.

Fletcher, E. L., Jobling, A. I., Vessey, K. A., Luu, C., Guymer, R. H. and Baird, P. N. (2011). Animal models of retinal disease. Prog Mol Biol Transl Sci 100, 211-86.

Frasson, M., Sahel, J. A., Fabre, M., Simonutti, M., Dreyfus, H. and Picaud, S. (1999). Retinitis pigmentosa: rod photoreceptor rescue by a calcium-channel blocker in the rd mouse. Nat Med 5, 1183-7.

Galy, A., Neron, B., Planque, N., Saule, S. and Eychene, A. (2002). Activated MAPK/ERK kinase (MEK-1) induces transdifferentiation of pigmented epithelium into neural retina. Dev Biol 248, 251-64.

Ghosh, A. K., Murga-Zamalloa, C. A., Chan, L., Hitchcock, P. F., Swaroop, A. and Khanna, H. (2010). Human retinopathy-associated ciliary protein retinitis pigmentosa GTPase regulator mediates cilia-dependent vertebrate development. Hum Mol Genet 19, 90-8.

Goldsmith, P. and Harris, W. A. (2003). The zebrafish as a tool for understanding the biology of visual disorders. Semin Cell Dev Biol 14, 11-8.

Hamel, C. (2006). Retinitis pigmentosa. Orphanet J Rare Dis 1, 40.

Hamm, L. M., Tam, B. M. and Moritz, O. L. (2009). Controlled rod cell ablation in transgenic Xenopus laevis. Invest Ophthalmol Vis Sci 50, 885-92.

Hartong, D. T., Berson, E. L. and Dryja, T. P. (2006). Retinitis pigmentosa. Lancet 368, 1795809.

Haynes, T., Gutierrez, C., Aycinena, J. C., Tsonis, P. A. and Del Rio-Tsonis, K. (2007). BMP signaling mediates stem/progenitor cell-induced retina regeneration. Proc Natl Acad Sci U S A 104, 20380-5.

Hong, D. H., Pawlyk, B. S., Shang, J., Sandberg, M. A., Berson, E. L. and Li, T. (2000). A retinitis pigmentosa GTPase regulator (RPGR)-deficient mouse model for X-linked retinitis pigmentosa (RP3). Proc Natl Acad Sci U S A 97, 3649-54.

Hosch, J., Lorenz, B. and Stieger, K. (2011). RPGR: role in the photoreceptor cilium, human retinal disease, and gene therapy. Ophthalmic Genet 32, 1-11.

Jarrett, S. G., Lewin, A. S. and Boulton, M. E. (2010). The importance of mitochondria in agerelated and inherited eye disorders. Ophthalmic Res 44, 179-90.

Kaneko, H., Dridi, S., Tarallo, V., Gelfand, B. D., Fowler, B. J., Cho, W. G., Kleinman, M. E., Ponicsan, S. L., Hauswirth, W. W., Chiodo, V. A. et al. (2011). DICER1 deficit induces Alu RNA toxicity in age-related macular degeneration. Nature 471, 325-30.

Karan, G., Lillo, C., Yang, Z., Cameron, D. J., Locke, K. G., Zhao, Y., Thirumalaichary, S., Li, C., Birch, D. G., Vollmer-Snarr, H. R. et al. (2005). Lipofuscin accumulation, abnormal electrophysiology, and photoreceptor degeneration in mutant ELOVL4 transgenic mice: a model for macular degeneration. Proc Natl Acad Sci U S A 102, 4164-9.

Karl, M. O. and Reh, T. A. (2010). Regenerative medicine for retinal diseases: activating endogenous repair mechanisms. Trends Mol Med 16, 193-202.

Kassen, S. C., Thummel, R., Campochiaro, L. A., Harding, M. J., Bennett, N. A. and Hyde, D. R. (2009). CNTF induces photoreceptor neuroprotection and Muller glial cell proliferation through two different signaling pathways in the adult zebrafish retina. Exp Eye Res 88, 1051-64.

Kaushal, S., Ridge, K. D. and Khorana, H. G. (1994). Structure and function in rhodopsin: the role of asparagine-linked glycosylation. Proc Natl Acad Sci U S A 91, 4024-8. 
Kedzierski, W., Lloyd, M., Birch, D. G., Bok, D. and Travis, G. H. (1997). Generation and analysis of transgenic mice expressing P216L-substituted rds/peripherin in rod photoreceptors. Invest Ophthalmol Vis Sci 38, 498-509.

Kong, J., Kim, S. R., Binley, K., Pata, I., Doi, K., Mannik, J., Zernant-Rajang, J., Kan, O., Iqball, S., Naylor, S. et al. (2008). Correction of the disease phenotype in the mouse model of Stargardt disease by lentiviral gene therapy. Gene Ther 15, 1311-20.

Leveillard, T., Mohand-Said, S., Lorentz, O., Hicks, D., Fintz, A. C., Clerin, E., Simonutti, M., Forster, V., Cavusoglu, N., Chalmel, F. et al. (2004). Identification and characterization of rod-derived cone viability factor. Nat Genet 36, 755-9.

Leveillard, T. and Sahel, J. A. (2010). Rod-derived cone viability factor for treating blinding diseases: from clinic to redox signaling. Sci Transl Med 2, $26 \mathrm{ps} 16$.

Li, L., Li, Y., Chen, D., Shao, J., Li, X. and Xu, C. (2010). Fishing for age-related visual system mutants: behavioral screening of retinal degeneration genes in zebrafish. Curr Aging Sci 3, 43-5.

Lien, S. and Lowman, H. B. (2008). Therapeutic anti-VEGF antibodies. Handb Exp Pharmacol, 131-50.

Lingor, P., Tonges, L., Pieper, N., Bermel, C., Barski, E., Planchamp, V. and Bahr, M. (2008). ROCK inhibition and CNTF interact on intrinsic signalling pathways and differentially regulate survival and regeneration in retinal ganglion cells. Brain 131, 250-63.

Liu, Q., Lyubarsky, A., Skalet, J. H., Pugh, E. N., Jr. and Pierce, E. A. (2003). RP1 is required for the correct stacking of outer segment discs. Invest Ophthalmol Vis Sci 44, 4171-83.

Liutkeviciene, R., Lesauskaite, V., Asmoniene, V., Zaliuniene, D. and Jasinskas, V. (2010). Factors determining age-related macular degeneration: a current view. Medicina (Kaunas) 46, 89-94.

Locker, M., Borday, C. and Perron, M. (2009). Stemness or not stemness? Current status and perspectives of adult retinal stem cells. Curr Stem Cell Res Ther 4, 118-30.

Locker, M., El Yakoubi, W., Mazurier, N., Dullin, J. P. and Perron, M. (2010). A decade of mammalian retinal stem cell research. Arch Ital Biol 148, 59-72.

Ma, L., Kaufman, Y., Zhang, J. and Washington, I. (2010). C20-D3-vitamin A slows lipofuscin accumulation and electrophysiological retinal degeneration in a mouse model of Stargardt disease. J Biol Chem 286, 7966-74.

Mao, H., James, T., Jr., Schwein, A., Shabashvili, A. E., Hauswirth, W. W., Gorbatyuk, M. S. and Lewin, A. S. (2011). AAV delivery of wild-type rhodopsin preserves retinal function in a mouse model of autosomal dominant retinitis pigmentosa. Hum Gene Ther 22, 567-75.

Martinez-De Luna, R. I., Kelly, L. E. and El-Hodiri, H. M. (2011). The Retinal Homeobox (Rx) gene is necessary for retinal regeneration. Dev Biol 353, 10-8.

Mitashov, V. I. and Maliovanova, S. D. (1982). [Cellular proliferative potentials of the pigment and ciliated epithelium of the eye in clawed toads normally and during regeneration]. Ontogenez 13, 228-34.

Molday, R. S., Hicks, D. and Molday, L. (1987). Peripherin. A rim-specific membrane protein of rod outer segment discs. Invest Ophthalmol Vis Sci 28, 50-61.

Molday, R. S. and Zhang, K. (2010). Defective lipid transport and biosynthesis in recessive and dominant Stargardt macular degeneration. Prog Lipid Res 49, 476-92. 
Monnin, J., Morand-Villeneuve, N., Michel, G., Hicks, D. and Versaux-Botteri, C. (2007). Production of neurospheres from mammalian Muller cells in culture. Neurosci Lett 421, 22-6.

Montgomery, J. E., Parsons, M. J. and Hyde, D. R. (2010). A novel model of retinal ablation demonstrates that the extent of rod cell death regulates the origin of the regenerated zebrafish rod photoreceptors. J Comp Neurol 518, 800-14.

Moshiri, A., Close, J. and Reh, T. A. (2004). Retinal stem cells and regeneration. Int J Dev Biol 48, 1003-14.

Muller, A., Hauk, T. G., Leibinger, M., Marienfeld, R. and Fischer, D. (2009). Exogenous CNTF stimulates axon regeneration of retinal ganglion cells partially via endogenous CNTF. Mol Cell Neurosci 41, 233-46.

Murga-Zamalloa, C. A., Atkins, S. J., Peranen, J., Swaroop, A. and Khanna, H. (2010). Interaction of retinitis pigmentosa GTPase regulator (RPGR) with RAB8A GTPase: implications for cilia dysfunction and photoreceptor degeneration. Hum Mol Genet 19, 3591-8.

Murga-Zamalloa, C. A., Swaroop, A. and Khanna, H. (2009). RPGR-containing protein complexes in syndromic and non-syndromic retinal degeneration due to ciliary dysfunction. J Genet 88, 399-407.

Olsson, J. E., Gordon, J. W., Pawlyk, B. S., Roof, D., Hayes, A., Molday, R. S., Mukai, S., Cowley, G. S., Berson, E. L. and Dryja, T. P. (1992). Transgenic mice with a rhodopsin mutation (Pro23His): a mouse model of autosomal dominant retinitis pigmentosa. Neuron 9, 815-30.

Ooto, S., Akagi, T., Kageyama, R., Akita, J., Mandai, M., Honda, Y. and Takahashi, M. (2004). Potential for neural regeneration after neurotoxic injury in the adult mammalian retina. Proc Natl Acad Sci U S A 101, 13654-9.

Osakada, F., Ooto, S., Akagi, T., Mandai, M., Akaike, A. and Takahashi, M. (2007). Wnt signaling promotes regeneration in the retina of adult mammals. J Neurosci 27, 4210-9.

Otteson, D. C. and Hitchcock, P. F. (2003). Stem cells in the teleost retina: persistent neurogenesis and injury-induced regeneration. Vision Res 43, 927-36.

Palczewski, K. (2010). Retinoids for treatment of retinal diseases. Trends Pharmacol Sci 31, 284-95.

Paquet-Durand, F., Beck, S., Michalakis, S., Goldmann, T., Huber, G., Muhlfriedel, R., Trifunovic, D., Fischer, M. D., Fahl, E., Duetsch, G. et al. (2011). A key role for cyclic nucleotide gated (CNG) channels in cGMP-related retinitis pigmentosa. Hum Mol Genet 20, 941-7.

Paquet-Durand, F., Hauck, S. M., van Veen, T., Ueffing, M. and Ekstrom, P. (2009). PKG activity causes photoreceptor cell death in two retinitis pigmentosa models. J Neurochem 108, 796-810.

Park, C.M., Hollenberg, M.J. (1989). Basic fibroblast growth factor induces retinal regeneration in vivo. Dev. Biol. 134, 201-5.

Park, C.M., Hollenberg, M.J. (1991). Induction of retinal regeneration in vivo by growth factors. Dev. Biol. 148, 322-33.

Pawlyk, B. S., Bulgakov, O. V., Liu, X., Xu, X., Adamian, M., Sun, X., Khani, S. C., Berson, E. L., Sandberg, M. A. and Li, T. (2010). Replacement gene therapy with a human 
RPGRIP1 sequence slows photoreceptor degeneration in a murine model of Leber congenital amaurosis. Hum Gene Ther 21, 993-1004.

Pechan, P., Rubin, H., Lukason, M., Ardinger, J., DuFresne, E., Hauswirth, W. W., Wadsworth, S. C. and Scaria, A. (2009). Novel anti-VEGF chimeric molecules delivered by AAV vectors for inhibition of retinal neovascularization. Gene Ther 16, 10-6.

Pisharath, H. (2007). Validation of nitroreductase, a prodrug-activating enzyme, mediated cell death in embryonic zebrafish (Danio rerio). Comp Med 57, 241-6.

Pisharath, H., Rhee, J. M., Swanson, M. A., Leach, S. D. and Parsons, M. J. (2007). Targeted ablation of beta cells in the embryonic zebrafish pancreas using E. coli nitroreductase. Mech Dev 124, 218-29.

Prasad, P. S., Schwartz, S. D. and Hubschman, J. P. (2010). Age-related macular degeneration: current and novel therapies. Maturitas 66, 46-50.

Punzo, C., Kornacker, K. and Cepko, C. L. (2009). Stimulation of the insulin/mTOR pathway delays cone death in a mouse model of retinitis pigmentosa. Nat Neurosci 12, 44-52.

Qin, Z., Barthel, L. K. and Raymond, P. A. (2009). Genetic evidence for shared mechanisms of epimorphic regeneration in zebrafish. Proc Natl Acad Sci U S A 106, 9310-5.

Querques, G., Avellis, F. O., Querques, L., Bandello, F. and Souied, E. H. (2011). Age-related macular degeneration. Clin Ophthalmol 5, 593-601.

Ramachandran, R., Fausett, B. V. and Goldman, D. (2010a). Ascl1a regulates Muller glia dedifferentiation and retinal regeneration through a Lin-28-dependent, let-7 microRNA signalling pathway. Nat Cell Biol 12, 1101-7.

Ramachandran, R., Reifler, A., Parent, J. M. and Goldman, D. (2010b). Conditional gene expression and lineage tracing of tuba1a expressing cells during zebrafish development and retina regeneration. J Comp Neurol 518, 4196-212.

Rattner, A. and Nathans, J. (2006). Macular degeneration: recent advances and therapeutic opportunities. Nat Rev Neurosci 7, 860-72.

Raymond, P. A., Barthel, L. K., Bernardos, R. L. and Perkowski, J. J. (2006). Molecular characterization of retinal stem cells and their niches in adult zebrafish. BMC Dev Biol 6, 36.

Reh, T. A. and Nagy, T. (1987). A possible role for the vascular membrane in retinal regeneration in Rana catesbienna tadpoles. Dev Biol 122, 471-82.

Reme, C. E., Weller M., Szczesny P., Munz K., Hafezi F., Reinboth J. and M., C. (1995). in Degenerative Diseases of the Retina. ed Anderson R. E.(Plenum Press, New York), pp $19-25$.

Rivas, M. A. and Vecino, E. (2009). Animal models and different therapies for treatment of retinitis pigmentosa. Histol Histopathol 24, 1295-322.

Roof, D. J., Adamian, M. and Hayes, A. (1994). Rhodopsin accumulation at abnormal sites in retinas of mice with a human $\mathrm{P} 23 \mathrm{H}$ rhodopsin transgene. Invest Ophthalmol Vis Sci 35, 4049-62.

Sakaguchi, D. S., Janick, L. M. and Reh, T. A. (1997). Basic fibroblast growth factor (FGF-2) induced transdifferentiation of retinal pigment epithelium: generation of retinal neurons and glia. Dev Dyn 209, 387-98.

Sakami, S., Maeda, T., Bereta, G., Okano, K., Golczak, M., Sumaroka, A., Roman, A. J., Cideciyan, A. V., Jacobson, S. G. and Palczewski, K. (2011). Probing mechanisms of photoreceptor degeneration in a new mouse model of the common form of 
autosomal dominant retinitis pigmentosa due to $\mathrm{P} 23 \mathrm{H}$ opsin mutations. J Biol Chem 286, 10551-67.

Sancho-Pelluz, J., Arango-Gonzalez, B., Kustermann, S., Romero, F. J., van Veen, T., Zrenner, E., Ekstrom, P. and Paquet-Durand, F. (2008). Photoreceptor cell death mechanisms in inherited retinal degeneration. Mol Neurobiol 38, 253-69.

Sherpa, T., Fimbel, S. M., Mallory, D. E., Maaswinkel, H., Spritzer, S. D., Sand, J. A., Li, L., Hyde, D. R. and Stenkamp, D. L. (2008). Ganglion cell regeneration following whole-retina destruction in zebrafish. Dev Neurobiol 68, 166-81.

Simonelli, F., Maguire, A. M., Testa, F., Pierce, E. A., Mingozzi, F., Bennicelli, J. L., Rossi, S., Marshall, K., Banfi, S., Surace, E. M. et al. (2010). Gene therapy for Leber's congenital amaurosis is safe and effective through 1.5 years after vector administration. Mol Ther 18, 643-50.

Spence, J. R., Aycinena, J. C. and Del Rio-Tsonis, K. (2007a). Fibroblast growth factorhedgehog interdependence during retina regeneration. Dev Dyn 236, 1161-74.

Spence, J. R., Gutierrez, C. and Del Rio-Tsonis, K. (2007b). Retina regeneration in the embryonic chick In Strategies for Retinal Tissue Repair and Regeneration in Vertebrates: From Fish to Human.

Spence, J. R., Madhavan, M., Aycinena, J. C. and Del Rio-Tsonis, K. (2007c). Retina regeneration in the chick embryo is not induced by spontaneous Mitf downregulation but requires FGF/FGFR/MEK/Erk dependent upregulation of Pax6. Mol Vis 13, 57-65.

Spence, J. R., Madhavan, M., Ewing, J. D., Jones, D. K., Lehman, B. M. and Del Rio-Tsonis, K. (2004). The hedgehog pathway is a modulator of retina regeneration. Development 131, 4607-21.

Stearns, G., Evangelista, M., Fadool, J. M. and Brockerhoff, S. E. (2007). A mutation in the cone-specific pde6 gene causes rapid cone photoreceptor degeneration in zebrafish. J Neurosci 27, 13866-74.

Stoick-Cooper, C. L., Moon, R. T. and Weidinger, G. (2007). Advances in signaling in vertebrate regeneration as a prelude to regenerative medicine. Genes Dev 21, $1292-$ 315.

Takano, Y., Ohguro, H., Dezawa, M., Ishikawa, H., Yamazaki, H., Ohguro, I., Mamiya, K., Metoki, T., Ishikawa, F. and Nakazawa, M. (2004). Study of drug effects of calcium channel blockers on retinal degeneration of rd mouse. Biochem Biophys Res Commun 313, 1015-22.

Tam, B. M. and Moritz, O. L. (2006). Characterization of rhodopsin P23H-induced retinal degeneration in a Xenopus laevis model of retinitis pigmentosa. Invest Ophthalmol Vis Sci 47, 3234-41.

Tam, B. M. and Moritz, O. L. (2007). Dark rearing rescues P23H rhodopsin-induced retinal degeneration in a transgenic Xenopus laevis model of retinitis pigmentosa: a chromophore-dependent mechanism characterized by production of N-terminally truncated mutant rhodopsin. J Neurosci 27, 9043-53.

Tam, B. M. and Moritz, O. L. (2009). The role of rhodopsin glycosylation in protein folding, trafficking, and light-sensitive retinal degeneration. J Neurosci 29, 15145-54.

Tam, B. M., Xie, G., Oprian, D. D. and Moritz, O. L. (2006). Mislocalized rhodopsin does not require activation to cause retinal degeneration and neurite outgrowth in Xenopus laevis. J Neurosci 26, 203-9. 
Thummel, R., Enright, J. M., Kassen, S. C., Montgomery, J. E., Bailey, T. J. and Hyde, D. R. (2010). Pax6a and Pax6b are required at different points in neuronal progenitor cell proliferation during zebrafish photoreceptor regeneration. Exp Eye Res 90, 572-82.

Thummel, R., Kassen, S. C., Enright, J. M., Nelson, C. M., Montgomery, J. E. and Hyde, D. R. (2008a). Characterization of Muller glia and neuronal progenitors during adult zebrafish retinal regeneration. Exp Eye Res 87, 433-44.

Thummel, R., Kassen, S. C., Montgomery, J. E., Enright, J. M. and Hyde, D. R. (2008b). Inhibition of Muller glial cell division blocks regeneration of the light-damaged zebrafish retina. Dev Neurobiol 68, 392-408.

Travis, G. H., Brennan, M. B., Danielson, P. E., Kozak, C. A. and Sutcliffe, J. G. (1989). Identification of a photoreceptor-specific mRNA encoded by the gene responsible for retinal degeneration slow (rds). Nature 338, 70-3.

Tropepe, V., Coles, B. L., Chiasson, B. J., Horsford, D. J., Elia, A. J., McInnes, R. R. and van der Kooy, D. (2000). Retinal stem cells in the adult mammalian eye. Science 287, 2032-6.

Tsubura, A., Lai, Y. C., Miki, H., Sasaki, T., Uehara, N., Yuri, T. and Yoshizawa, K. (2011). Review: Animal models of N-Methyl-N-nitrosourea-induced mammary cancer and retinal degeneration with special emphasis on therapeutic trials. In Vivo 25, 11-22.

Vasireddy, V., Wong, P. and Ayyagari, R. (2010). Genetics and molecular pathology of Stargardt-like macular degeneration. Prog Retin Eye Res 29, 191-207.

Vergara, M. N. and Del Rio-Tsonis, K. (2009). Retinal regeneration in the Xenopus laevis tadpole: a new model system. Mol Vis 15, 1000-13.

Vervoort, R., Lennon, A., Bird, A. C., Tulloch, B., Axton, R., Miano, M. G., Meindl, A., Meitinger, T., Ciccodicola, A. and Wright, A. F. (2000). Mutational hot spot within a new RPGR exon in X-linked retinitis pigmentosa. Nat Genet 25, 462-6.

Vihtelic, T. S. and Hyde, D. R. (2000). Light-induced rod and cone cell death and regeneration in the adult albino zebrafish (Danio rerio) retina. J Neurobiol 44, 289307.

Wang, D. Y., Chan, W. M., Tam, P. O., Baum, L., Lam, D. S., Chong, K. K., Fan, B. J. and Pang, C. P. (2005). Gene mutations in retinitis pigmentosa and their clinical implications. Clin Chim Acta 351, 5-16.

Weng, J., Mata, N. L., Azarian, S. M., Tzekov, R. T., Birch, D. G. and Travis, G. H. (1999). Insights into the function of Rim protein in photoreceptors and etiology of Stargardt's disease from the phenotype in abcr knockout mice. Cell 98, 13-23.

Wetts, R. and Fraser, S. E. (1988). Multipotent precursors can give rise to all major cell types of the frog retina. Science 239, 1142-5.

Wetts, R., Serbedzija, G. N. and Fraser, S. E. (1989). Cell lineage analysis reveals multipotent precursors in the ciliary margin of the frog retina. Dev Biol 136, 254-63.

Wright, A. F., Chakarova, C. F., Abd El-Aziz, M. M. and Bhattacharya, S. S. (2010). Photoreceptor degeneration: genetic and mechanistic dissection of a complex trait. Nat Rev Genet 11, 273-84.

Wu, D. M., Schneiderman, T., Burgett, J., Gokhale, P., Barthel, L. and Raymond, P. A. (2001). Cones regenerate from retinal stem cells sequestered in the inner nuclear layer of adult goldfish retina. Invest Ophthalmol Vis Sci 42, 2115-24.

Xiao, Q., Hartzell, H. C. and Yu, K. (2010). Bestrophins and retinopathies. Pflugers Arch 460, 559-69. 
Yasukawa, T., Tabata, Y., Kimura, H. and Ogura, Y. (2011). Recent advances in intraocular drug delivery systems. Recent Pat Drug Deliv Formul 5, 1-10.

Yoshii, C., Ueda, Y., Okamoto, M. and Araki, M. (2007). Neural retinal regeneration in the anuran amphibian Xenopus laevis post-metamorphosis: transdifferentiation of retinal pigmented epithelium regenerates the neural retina. Dev Biol 303, 45-56.

Yurco, P. and Cameron, D. A. (2005). Responses of Muller glia to retinal injury in adult zebrafish. Vision Res 45, 991-1002.

Zhang, R., Oglesby, E. and Marsh-Armstrong, N. (2008). Xenopus laevis P23H rhodopsin transgene causes rod photoreceptor degeneration that is more severe in the ventral retina and is modulated by light. Exp Eye Res 86, 612-21.

Zhang, Y., Stanton, J. B., Wu, J., Yu, K., Hartzell, H. C., Peachey, N. S., Marmorstein, L. Y. and Marmorstein, A. D. (2010). Suppression of Ca2+ signaling in a mouse model of Best disease. Hum Mol Genet 19, 1108-18.

Zhao, X. F., Ellingsen, S. and Fjose, A. (2009). Labelling and targeted ablation of specific bipolar cell types in the zebrafish retina. BMC Neurosci 10, 107.

Zhao, Y., Hong, D. H., Pawlyk, B., Yue, G., Adamian, M., Grynberg, M., Godzik, A. and Li, T. (2003). The retinitis pigmentosa GTPase regulator (RPGR)- interacting protein: subserving RPGR function and participating in disk morphogenesis. Proc Natl Acad Sci U S A 100, 3965-70. 


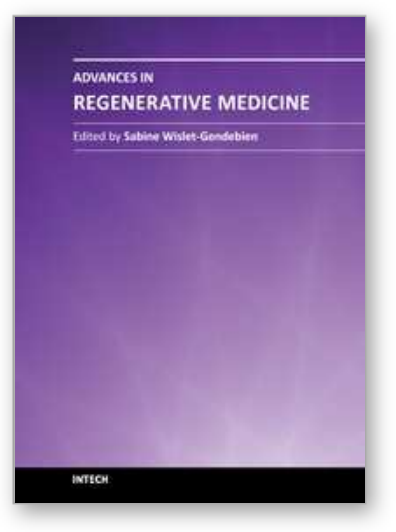

\author{
Advances in Regenerative Medicine \\ Edited by Dr Sabine Wislet-Gendebien
}

ISBN 978-953-307-732-1

Hard cover, 404 pages

Publisher InTech

Published online 21, November, 2011

Published in print edition November, 2011

Even if the origins of regenerative medicine can be found in Greek mythology, as attested by the story of Prometheus, the Greek god whose immortal liver was feasted on day after day by Zeus' eagle; many challenges persist in order to successfully regenerate lost cells, tissues or organs and rebuild all connections and functions. In this book, we will cover a few aspects of regenerative medicine highlighting major advances and remaining challenges in cellular therapy and tissue/organ engineering.

\title{
How to reference
}

In order to correctly reference this scholarly work, feel free to copy and paste the following:

Gabriele Colozza, André Mazabraud and Muriel Perron (2011). Degeneration and Regeneration in the Vertebrate Retina, Advances in Regenerative Medicine, Dr Sabine Wislet-Gendebien (Ed.), ISBN: 978-953307-732-1, InTech, Available from: http://www.intechopen.com/books/advances-in-regenerativemedicine/degeneration-and-regeneration-in-the-vertebrate-retina

\section{INTECH}

open science | open minds

\section{InTech Europe}

University Campus STeP Ri

Slavka Krautzeka 83/A

51000 Rijeka, Croatia

Phone: +385 (51) 770447

Fax: +385 (51) 686166

www.intechopen.com

\section{InTech China}

Unit 405, Office Block, Hotel Equatorial Shanghai

No.65, Yan An Road (West), Shanghai, 200040, China

中国上海市延安西路65号上海国际贵都大饭店办公楼 405 单元

Phone: +86-21-62489820

Fax: $+86-21-62489821$ 
(C) 2011 The Author(s). Licensee IntechOpen. This is an open access article distributed under the terms of the Creative Commons Attribution 3.0 License, which permits unrestricted use, distribution, and reproduction in any medium, provided the original work is properly cited. 